Results 192/196 paediatric services enrolled. 186 units provided service descriptor data, 174 clinical audit data and 145 PREM data. The clinical cohort consisted of 3449 patients; median age 5.2 years; male: female 55:45\%. Anonymised PREM data were received from 2335 parents, carers, children and young people. $45 \%$ of first assessments occurred within an acute presentation. $35 \%$ of children had epilepsy diagnosed by 12 months. $22.6 \%$ of children had a documented neurodisability.

$68 \%$ of paediatric services now have at least one Epilepsy Specialist Nurse (ESN). There has been a significant increase in percentage of children having ESN input; access to a paediatrician with expertise in epilepsies; appropriate assessment, classification and investigations in 2014 compared to 2012. PREM data showed 88\% (1897/2148) overall satisfaction with services; $20 \%$ thought that staff are not good at working together.

Conclusion There is evidence of significant improvements in the provision of medical and nursing epilepsy care. However, many children still do not receive recommended practice and access fully resourced paediatric epilepsy services.

\section{G284 KAWASAKI DISEASE BPSU SURVEY IN GREAT BRITAIN AND IRELAND}

${ }^{1}$ RMR Tulloh, ${ }^{2} \mathrm{R}$ Mayon-White, ${ }^{1} \mathrm{PM}$ Craggs, ${ }^{3} \mathrm{D}$ Shingadia, ${ }^{4} \mathrm{C}$ Michie, ${ }^{2} \mathrm{~A}$ Harnden, ${ }^{5} \mathrm{O}$ Franklin, ${ }^{6} \mathrm{~A}$ Ramanan, ${ }^{7} \mathrm{EJ}$ Tizard, ${ }^{1} \mathrm{GM}$ Connolly, ${ }^{8} \mathrm{~K}$ Gargh, ${ }^{9} \mathrm{~S}$ Davidson, ${ }^{10} \mathrm{RM}$ Lynn, ${ }^{11} \mathrm{M}$ Levin, ${ }^{12} \mathrm{P}$ Brogan. ${ }^{1}$ Cardiology, Bristol Royal Hospital for Children, Bristol, UK; ${ }^{2}$ Primary Care, University of Oxford, Oxford, UK; ${ }^{3}$ Infectious Disease, Great Ormond Street Hospital, London, UK; ${ }^{4}$ Paediatrics, Ealing Hospital, London, UK; ${ }^{5}$ Cardiology, Our Lady's, Crumlin, Dublin, Ireland; ${ }^{6}$ Rheumatology, Bristol Royal Hospital for Children, Bristol, UK; ${ }^{7}$ Nephrology, Bristol Royal Hospital for Children, Bristol, UK; ${ }^{8}$ Paediatrics, Wexham Hospital, Wexham, UK; ${ }^{9}$ Kawasaki Disease Parent Support Group, Coventry, UK; ${ }^{10}$ British Paediatric Surveillance Unit, London, UK; ${ }^{11}$ Paediatrics, Imperial College London, London, UK; ${ }^{12}$ Vasculitis, Great Ormond Street Hospital, London, UK

\subsection{6/archdischild-2015-308599.261}

Introduction Kawasaki disease (KD) is the commonest cause of acquired heart disease in the western world. We report here on the preliminary data for the first year of a 2-year national survey in Great Britain and Northern Ireland.

Methods Using standard BPSU methodology, children with Complete KD (for the first year) presenting from January $1^{\text {st }}$ to December $31^{\text {st }} 2013$ were studied with their treatments and complications. The steering committee reviewed cases that were unclear or incomplete.

Results Excluding incomplete $\mathrm{KD}$ and incomplete data sets, there were 180 with complete KD (15/month). Peak presentation was in March, boy:girl ratio was 1.8 and $69 \%$ were 1 to 4 years old. The highest incidence was in children under 5 years especially in London and East Anglia $(5.6 / 100,000)$ and lowest in the Midlands $(2.8 / 100,000)$. Highest incidence was in Chinese $(21.9 / 100,000)$, Black African and Caribbean $(14.5 / 100,000)$ and Mixed ethnicity (15.3/100,000). 81\% saw a GP at median 2 days after fever commencement and admission was median (range) of 2 (0-27) days later. Fever duration was 6 (1-28) days. $97 \%$ had rash, usually at the start of fever, which was on the trunk or widespread in $89 \%$ and was macular in $75 \%$. Bilateral non-purulent conjunctivitis (91\%) occurred at $4(0-27)$ days and mucositis $(97 \%)$ at $5(0-27)$ days. Periphery involvement was up to 32 days in 156 (86\%). Lymphadenopathy was least common (65\%) often after 5 days. The BCG scar was inflamed in 11.

CRP ranged from $1-501 \mathrm{mg} / \mathrm{l}$, albumin from $17-45 \mathrm{~g} / \mathrm{l}$, lowest platelet counts were below $150 \times 10^{\wedge} 9 / 1$ in 14 .
$31(22 \%)$ had dilated coronary arteries, 9 had pericardial effusion and 12 had ECG abnormalities.

Intravenous immunoglobulin $(2 \mathrm{~g} / \mathrm{kg})$ given within 7 days to $95 \%$, but not to 9 complete cases (delayed diagnosis). Second dose was given to 13 children. High dose aspirin $(30-50 \mathrm{mg} / \mathrm{kg}$ ) followed by low dose aspirin was given to $92 \%$.

19 had sequelae, 15 with persistence of coronary artery dilation, with no deaths.

Conclusions These preliminary results show a high incidence of coronary artery disease with the old guideline for $\mathrm{KD}$ and give new data on seasonality, ethnicity and correlation with clinical symptoms.

\section{G285 PAEDIATRIC PREPARATION DAY: SMOOTHING THE TRANSITION FOR YORKSHIRE AND THE HUMBER FOUNDATION AND GP TRAINEES}

${ }^{1} \mathrm{~T}$ Stephenson, ${ }^{1} \mathrm{D}$ Singh, ${ }^{2} \mathrm{~N}$ Medd, ${ }^{3} \mathrm{~V}$ Davies, ${ }^{3} \mathrm{~L}$ Blakemore, ${ }^{2} \mathrm{~S}$ Sandhu, ${ }^{2} \mathrm{~S}$ Clark, ${ }^{3} \mathrm{H}$ Shore. ${ }^{1}$ Hull Institute of Learning and Simulation, Hull \& East Yorkshire Hospitals NHS Trust, Hull, UK; ${ }^{2}$ Sheffield Children's Hospital, Sheffield Children's NHS Foundation Trust, Sheffield, UK; ${ }^{3}$ Leeds Children's Hospital, Leeds Teaching Hospitals NHS Trust, Leeds, UK

\subsection{6/archdischild-2015-308599.262}

Background Delivery of safe, high quality healthcare relies upon adequate training and education. ${ }^{1}$ Concern exists regarding the preparedness of junior doctors for their expected clinical roles despite Tomorrow's Doctors and the implementation of the Foundation Programme. ${ }^{2,3}$ Foundation and General Practice (GP) trainees rotate through secondary care paediatric rotations expected to perform clinical skills. Yet, the vast majority will have very limited practical paediatric experience. As traditional teaching methods including 'see one, do one, teach one' become increasingly unacceptable, simulation-based medical education (SBME) is being advocated to provide opportunities for deliberate practice and avoidance of patient harm. ${ }^{4}$ Internationally, paediatric bootcamps are starting to emerge. However, both regionally and nationally, bespoke opportunities for Foundation and GP trainees to develop practical paediatric skills prior to paediatric rotations are lacking.

Methods A one-day regional paediatric and neonatal skills course was developed and piloted for Foundation and GP trainees rotating into secondary care paediatrics. This provided trainees with the opportunity to observe and practice fundamental procedural and resuscitation skills on part-task trainers and lowfidelity manikins under the supervision of senior paediatric trainees. Course evaluation was achieved through a comparative pre and post-test design using confidence levels and a bespoke MCQ to assess knowledge acquisition for qualitative and quantitative data respectively.

Observation/Evaluation

58 doctors attended four pilot courses. Complete pre and post-course comparison data was achieved from 57 trainees. The mean MCQ score rose from 60.7\% (95\% confidence interval, $58.5 \%$ to $62.9 \%)$ to $83.9 \%(82.4 \%$ to $85.3 \%)$, p $<0.0001$. Although statistically significant increments in mean confidence levels were demonstrated for every skill, the largest increases were associated with performing lumbar punctures, paediatric and neonatal life support, cannulation and venesection.

Conclusion This simple intervention is a feasible way to support Foundation and GP trainees ahead of paediatric rotations. This should facilitate a smoother transition into their clinical roles, when complemented with departmental induction programmes. The opportunity to practice skills in a safe 